did not undergo thoracotomy, it would be interesting to know the delay between onset of primary infection and diagnosis for each patient in their series. They reported a range of 6 to 20 days.

In conclusion, we consider the systematic use of thoracotomy in DNM, as suggested by Marty-Ane and associates, ${ }^{1}$ inappropriate. We support the less aggressive conclusions of Estrera and colleagues, ${ }^{3}$ who recommend transthoracotomy approach only if the mediastinitis has spread below the tracheal bifurcation anteriorly or the fourth thoracic vertebra posteriorly.

\section{REFERENCES}

1. Marty-Ane CH, Alauzen M, Alric P, Serres-Cousine O, Mary $\mathrm{H}$. Descending necrotizing mediastinitis advantage of mediastinal drainage with thoracotomy. J THORaC Cardiovasc Surg 1994;107:55-61.

2. Pearse HE. Mediastinitis following cervical suppuration. Ann Surg 1938;108:588-611.

3. Estrera AS, Landay MJ, Grisham JM, et al. Descending necrotizing mediastinitis. Surg Gynecol Obstet $1983 ; 157: 545-52$.

\title{
MYASTHENIA GRAVIS, PSYCHIATRIC DISTURBANCES, IDIOPATHIC THROMBOCYTOPENIC PURPURA, AND LICHEN PLANUS ASSOCIATED WITH CERVICAL THYMOMA
}

\author{
Tommaso Claudio Mineo, MD, Fausto Biancari, MD, and Vito D'Andrea, MD, Rome, Italy
}

Jaretzki and Wolff ${ }^{1}$ in 1988 recommended the maximal thymectomy procedure in the treatment of myasthenia gravis with or without thymoma and of thymoma with or without myasthenia gravis. The wide mediastinal and cervical exposure ensures complete removal of all thymic tissue and eventually of ectopic thymus. Recently, this operation allowed us to find a small cervical thymoma and to perform a curative resection in a patient with multiple autoimmune disorders.

The patient was a 32-year-old woman who successfully underwent splenectomy, followed by administration of immune serum globulin, in 1988 for the treatment of idiopathic thrombocytopenic purpura unresponsive to corticosteroids. In December 1994, the patient was admitted to our hospital with petechiae, mucous membrane bleeding, bilateral ptosis, and nasal speech. She also had oral lichen planus. Results of laboratory examinations were remarkable for a platelet count of $11,000 \mathrm{cells} / \mathrm{ml}$. A direct Dixon test had positive results for the presence of antiplatelet autoantibodies. A bone marrow biopsy specimen showed an increased number of megakaryocytes and hypoproduction of platelets. No signs of myelodisplastic syndrome were observed, and a normal karyotype was revealed by chromosomal analysis. Her serum antibody against acetylcholine receptor was high $(19.4 \mathrm{pmol} / \mathrm{ml})$, and electromyography confirmed the diagnosis of myasthenia gravis. Chest radiography and computed tomography failed to reveal any intrathoracic and extrathoracic abnormalities. Treatment was started, but the patient's condition responded poorly to pyridostigmine bromide (60 mg orally every 6 hours) and prednisone (50 $\mathrm{mg} /$ day).

From the Department of Thoracic Surgery, University of Tor Vergata, Rome, Italy.

Accepted for publication August 9, 1995.

J Thorac CARdiovasc Surg 1996;111:486-7

Copyright (C) 1996 by Mosby-Year Book, Inc

$0022-5223 / 96 \$ 5.00+0 \quad \mathbf{1 2 / 5 4 / 6 8 5 5 5}$
When seen by us in February 1995, the patient had petechiae, severe shortness of breath, ptosis, myopathic facies, nasal speech, dysarthria, dysphagia of both liquids and solids with nasal regurgitation, and generalized weakness. The patient reported recent memory loss and had gustatory and olfactory hallucinations. She also became dysphoric. Pulmonary function tests revealed forced vital capacity of $2.2 \mathrm{~L}$ ( $90 \%$ predicted), and forced expiratory volume in 1 second of $1.7 \mathrm{~L}$ (42\% predicted). Arterial blood gases with the patient breathing room air revealed an arterial oxygen tension of $68 \mathrm{~mm} \mathrm{Hg}$, an arterial carbon dioxide tension of $29 \mathrm{~mm} \mathrm{Hg}$, and a $\mathrm{pH}$ of 7.50 . Plasmaphereses were performed in five sessions, and $4500 \mathrm{ml}$ of plasma was exchanged. After this treatment, the patient's respiratory status, myasthenic symptoms, and psychiatric symptoms improved, and pyridostigmine bromide was successfully readministered ( $60 \mathrm{mg}$ orally every 8 hours).

Two units of platelets concentrate were transfused prophylactically, and the patient underwent a total median sternotomy with extensive removal of all thymic tissue, mediastinal fat, and both mediastinal pleural sheets. The dissection was continued through a transverse low cervical incision and a $1 \times 3 \mathrm{~cm}$ flat, well-encapsulated, solid mass was found under the sternocleidomastoid muscle, connected to the left superior pole of the thymus gland and adherent to the left lobe of the thyroid. The mass, which was easily and completely excised, was histologically classified as an epithelial, medullary type, Masaoka stage I thymoma. Microscopic examination of the removed mediastinal tissue demonstrated involution of normal thymic tissue without any specific findings. The patient made an uneventful recovery and was discharged 11 days after the operation on a regimen of prednisone $(50 \mathrm{mg} /$ day) and pyridostigmine $(60 \mathrm{mg}$ orally every 8 hours). Two months later, platelet count had increased to 210,000 cells $/ \mathrm{ml}$ and results of direct Dixon test were negative. At the same time, oral lesions completely disappeared and she was able to stop taking steroids. Four 
months after operation, the patient was well and did not have further psychiatric symptoms. Pyridostigmine bromide was discontinued, and computed tomographic scan did not reveal any signs of recurrent tumor.

It has been estimated that ectopic thymic tissue in the neck has an incidence as high as $21.0 \%,{ }^{2}$ but thymoma arising from undescended cervical thymus is exceedingly rare. To the best of our knowledge, fewer than 10 cases of true cervical thymoma have been previously reported. The diagnosis of aberrant cervical thymus or thymoma is rarely made before operation. Awareness of this entity and the need for as complete as possible removal of thymic tissue compel the surgeon to perform a meticulous neck dissection in all myasthenic patients, with or without known thymoma.

The association of myasthenia gravis and other autoimmune disorders with thymoma has been usually described in the form of isolated reports. Although in most of these reports the extent of the procedure has not been clearly described, thymectomy has been reported as effective for control of myasthenia gravis but failing to improve the clinical course of the other associated diseases. ${ }^{3-5} \mathrm{We}$ believe, however, that even in immune-mediated disorders other than myasthenia gravis extended and meticulous surgical resection could result in good remission rates.

\section{REFERENCES}

1. Jaretzki A 3rd, Wolff M. "Maximal" thymectomy for myasthenia gravis: surgical anatomy and operative technique. J Thorac Cardiovasc Surg 1988;96:711-6.

2. Yamashita H, Murakami N, Noguchi S, et al. Cervical thymoma and incidence of cervical thymus. Acta Pathol Jpn 1983;33:189-94.

3. Monden Y, Uyama T, Nakahara K, et al. Clinical characteristics and prognosis of myasthenia gravis with other autoimmune diseases. Ann Thorac Surg 1986;41: 189m-92.

4. Gibson LE, Muller SA. Dermatologic disorders in patients with thymoma. Acta Derm Venereol (Stockh) 1987;67:351-6.

5. Levasseur P, Menestrier M, Gaud C, et al. Thymomes et maladies associées: a propos d'une série de 255 thymomes opérés. Rev Mal Resp 1988;5: $173-8$.

\section{PURULENT PERICARDITIS: REDISCOVERY OF AN OLD REMEDY}

Daniel D. M. Mann-Segal, MBBS, E. Anne Shanahan, BSc, MBBS, FRACS, LLB, Bruce Jones, MBBS, FRACS, and Day Ramasamy, MRCP, DA, DCH, Melbourne, Victoria, Australia

The mortality rate for untreated purulent pericarditis is almost $100 \%$. Treatment of choice today is a combination of drainage and intravenous antibiotics. The mode of optimum drainage remains controversial. Aspiration alone, wide-bore pericardotomy, operative evacuation with pericardectomy, and subxiphoid drainage alone or with irrigation have all been advocated as treatments of first choice for both simple and loculated purulent pericarditis. $^{1}$

Subxiphoid pericardial irrigation with streptokinase and streptodornase was first documented more than 40 years ago. ${ }^{2,3}$ Despite its universal success, this treatment has been largely overlooked. We report the revival of this approach and describe its potential as a conservative option, particularly for the loculated condition.

A 76-year-old man sought treatment for mild exertional dyspnea. A $2 \mathrm{~cm}$ lingular lesion consistent with carcinoma was discovered by chest radiography, and he was hospitalized for further investigation. Physical examination

From the Thoracic Surgery and Intensive Care Units of Dandenong Hospital, Melbourne, Victoria, Australia.

Accepted for publication July 27, 1995.

J THORAC CARdiovasc Surg 1996;111:487-8

Copyright (C 1996 by Mosby-Year Book, Inc.

$0022-5223 / 96 \$ 5.00+0 \quad \mathbf{1 2 / 5 4 / 6 8 1 9 9}$ revealed fine bibasal crepitations. Electrocardiography showed left bundle branch block. Results of bronchoscopy were unremarkable. Two percutaneous lingular biopsies were carried out under computed tomographic guidance. Histologic examination was inconclusive, revealing " $a b$ normal cells suggestive of malignancy." Thoracotomy was performed and the lingular lobe was resected. Histologic preparation revealed a hamartoma.

Clinical biventricular failure developed on the eighth postoperative day. Chest radiography revealed cardiomegaly and pulmonary veinous congestion. An echocardiogram demonstrated a $3 \mathrm{~cm}$ wide pericardial effusion incorporating isolated "shaggy zones" consistent with fibrin deposition. The patient remained afebrile, but his leukocyte count rose to 26,000 cells/ml. Two attempts at paracentesis failed to aspirate any fluid before entering the myocardium. Subsequent ultrasonographically guided aspiration produced a hemoserous discharge of only $3 \mathrm{ml}$, which grew a multiply sensitive Staphylococcus aureus isolate. The patient's condition continued to deteriorate despite appropriate antibiosis and increasing ionotropic support. A further echocardiogram confirmed tamponade.

By this stage open drainage was no longer safe. A 7F pericardiocentesis tube was therefore inserted through a subxiphoid approach. This initially resulted in no drainage. A combination of 100,000 units of streptokinase with 